\title{
Application of hydration heat inhibitor in crack control of mass concrete of tunnel side wall
}

\author{
XiZhi Wang ${ }^{1 a^{*}}$, MinSheng Shi ${ }^{2 b}$, XinGang Wang ${ }^{2}$ \\ ${ }^{1}$ China University of Mining and Technology-Beijing, School of mechanics and civil engineering, Beijing, China \\ ${ }^{2} \mathrm{CCCC}$ Tianjin Harbor Engineering Research Institute Co., Ltd., Tianjin, China
}

\begin{abstract}
The structural deformation caused by temperature change is the main reason for cracking of mass concrete. In order to avoid or reduce the crack of the side wall of cast-in-place mass concrete in tunnel, the effects of different dosage of hydration heat inhibitor on the internal temperature rise curve of concrete, strength and the properties of the mixture are analyzed through experimental research, and the optimal dosage of $1 \%$ of cementing material is finally determined. The engineering application results show that after adding hydration heat inhibitor to the tunnel side wall concrete, the maximum temperature rise in the tunnel side wall is obviously reduced, and the arrival time of the temperature peak is delayed. No cracks appear in the tunnel side wall, and the crack control effect is good.
\end{abstract}

\section{Introduction}

The fundamental cause of cracking of mass concrete structures is that the structural shrinkage deformation is constrained, and the constrained deformation exceeds the ultimate tensile strength of concrete ${ }^{[1]}$. There are three main types of shrinkage deformation of concrete after initial setting ${ }^{[2]}$ : the first is drying shrinkage, which is caused by the evaporation of excess water inside the concrete to the outside, and the dry shrinkage strain of concrete under standard conditions is about $200 \times 10^{-6}$; the second is autogenous shrinkage of concrete, which is caused by the hydration reaction of cementitious materials consuming part of water, the autogenous shrinkage strain of ordinary concrete is about $100 \times 10^{-6}$, and the smaller the water binder ratio is, the greater the autogenous shrinkage is ${ }^{[3]}$; the third is the cooling shrinkage. Due to the large structure size and low thermal conductivity of concrete, the heat released by the hydration reaction of glue material can not be lost quickly, and the internal temperature will be very high ${ }^{[4]}$. Especially for the mass concrete structure with high strength grade, the maximum internal temperature can reach $70 \sim 90^{\circ} \mathrm{C}$, but this temperature will eventually drop to normal temperature, and the cooling shrinkage strain caused by this process can reach $400 \sim 600 \times 10^{-6}$. The three shrinkage strains of mass concrete can reach $700 \sim 900 \times 10^{-6}$, which is far greater than the ultimate tensile strength of concrete. From the above analysis, it can be seen that the cooling shrinkage accounts for the largest proportion in the three kinds of early shrinkage deformation of concrete. Therefore, it is the key point and main research idea of crack control to try to reduce the cooling shrinkage of concrete ${ }^{[5]}$. Burying cooling water pipe is a common method to reduce the cooling shrinkage of mass concrete at present. However, this method needs to buy a large number of pipes, which is buried and installed by workers, which consumes more manpower, material and financial resources, and may extend the construction period. Therefore, the development of an admixture to reduce the temperature shrinkage of concrete, to achieve the purpose of replacing the cooling water pipe, so as to avoid the various disadvantages of embedding cooling water pipe, which is of great significance to speed up the project progress and improve economic benefits.

Hydration heat inhibitor is a kind of concrete admixture developed to reduce the maximum temperature of mass concrete. It is mainly composed of hydroxy acid salt and fine minerals. The principle of its function is that it slowly dissolves in the alkaline solution environment produced by cement hydration, and adsorbs on the surface of cement particles and their hydration products, thus inhibiting the hydration exothermic rate of cement particles $^{[6]}$. Since the amount of hydration heat inhibitor can be dissolved in alkaline solution is very small, it can be dissolved and adsorbed continuously, thus slowing down the hydration reaction speed of cement particles and greatly delaying the concentration degree of cement hydration reaction, so as to achieve the goal of reducing the maximum temperature of concrete and reducing cooling shrinkage ${ }^{[7]}$.

In this paper, the effects of different dosage of heat of hydration inhibitor on the temperature rise curve, strength and properties of concrete mixture were studied by field model test, and the optimal dosage was determined. Then, an in-situ experimental study was carried out in the control of concrete cracks on the side walls of a tunnel to verify the results of the field model test.

\footnotetext{
* Corresponding author: ${ }^{a}$ tjwxz1210@163.com

bshiminsheng@tpei.com.cn
} 


\section{Field model test research}

\subsection{Raw materials}

Seagull P.O42.5 cement; class F Class I fly ash; S95 grade slag powder; river sand, zone II medium sand, fineness modulus of 2.7 , clay block content of $0.1 \%$, mud content of $0.5 \%$; crushed stone, $5 \sim 10 \mathrm{~mm}, 10 \sim 20 \mathrm{~mm}$ granite, crushing index $7.8 \%$, mud content $0.3 \%$, clay block content $0.1 \%$; subert polycarboxylic acid series high performance water reducing agent, water reduction rate of
23\%; hydration heat inhibitor, Wuhan Sanyuan, white powder polyhydroxy carboxylic acid ester, specific surface area is $270 \mathrm{~m}^{2} / \mathrm{kg}$.

\subsection{Test mix ratio}

For this model test, as listed in Table 1, on the basis of the C50 benchmark mix ratio, $0,0.5 \%, 1.0 \%$ and $1.5 \%$ of the total weight of the cementing material were mixed with heat of hydration inhibitors.

Table 1. Mix proportion of C50 mass concrete for test $\left(\mathrm{kg} / \mathrm{m}^{3}\right)$

\begin{tabular}{c|c|c|c|c|c|c|c|c}
\hline No. & Cement & Fly ash & Mineral powder & Sand & Crushed stone & Water & Crushed stone & Inhibitor \\
\hline C-0 & 292 & 63 & 63 & 789 & 1074 & 142 & 8.7 & 0 \\
\hline C-1 & 292 & 63 & 63 & 789 & 1074 & 142 & 8.7 & 2.09 \\
\hline C-2 & 292 & 63 & 63 & 789 & 1074 & 142 & 8.7 & 4.18 \\
\hline C-3 & 292 & 63 & 63 & 789 & 1074 & 142 & 8.7 & 6.27 \\
\hline
\end{tabular}

\section{3 test method}

(1)Internal temperature rise test of concrete

The size of concrete internal temperature test model is: length $\times$ width $\times$ height $=1 \mathrm{~m} \times 1 \mathrm{~m} \times 1 \mathrm{~m}$, and $20 \mathrm{~mm}$ thick Wooden formwork is used. Temperature testing equipment adopts the wireless mass concrete temperature testing system produced by Jinan Huanyutong Co., Ltd. Temperature sensors are arranged in the centre of the model and $50 \mathrm{~mm}$ from the inner surface of the template respectively to test the centre temperature and surface temperature of the model. The temperature test model and temperature acquisition equipment are shown in Fig. 1 and Fig. 2.

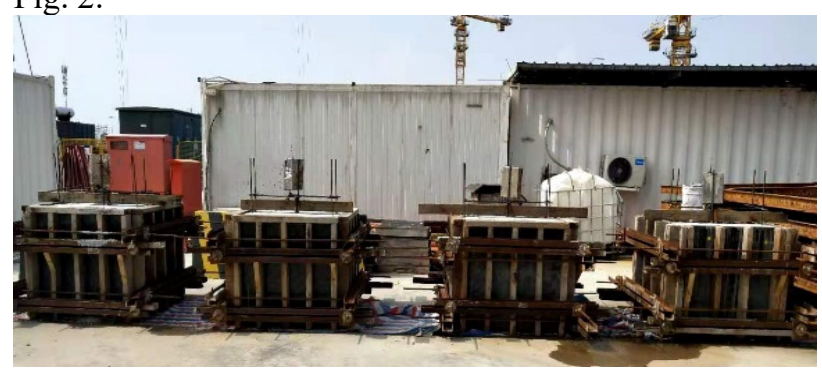

Fig. 1 Temperature test model of hydration heat inhibitor

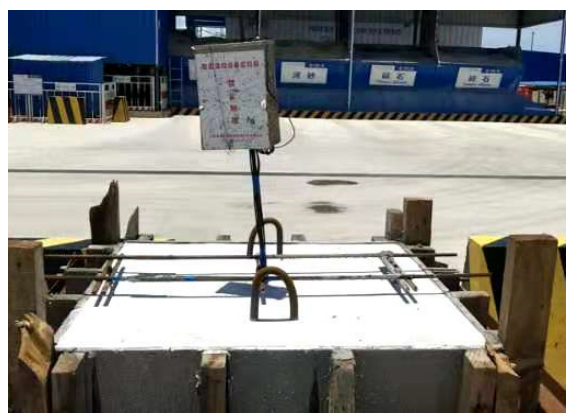

Fig. 2 Concrete temperature acquisition instrument
(2)Test results of compressive strength of concrete According to the concrete mix ratio in Table 1 , a certain amount of concrete was mixed to make enough $150 \mathrm{~mm} \times 150 \mathrm{~mm} \times 150 \mathrm{~mm}$ specimens, which were cured under standard conditions, and the compressive strength of concrete for $3,5,7,14$ and $28 \mathrm{~d}$ was tested respectively.

(3)Performance testing of concrete mixtures

According to the concrete mix ratio in Table 1, respectively weigh the raw materials, first add sand, stones and cementing materials to the mixer (mixed with hydration heat inhibitor in advance), water and water reducing agent are added after mixing for $30 \mathrm{~s}$, and then the concrete is poured out from the mixer after mixing for $150 \mathrm{~s}$, and slump and expansion are tested. After completion, the concrete mixture is put into the container and sealed for storage, and the slump test is conducted after the corresponding time.

\section{Analysis of test results}

\section{1 effect of hydration heat inhibitor on concrete temperature rise}

The influence of different dosage of hydration heat inhibitor on the center temperature curve of model concrete is shown in Fig. 3, and the influence on the surface temperature curve of model concrete is shown in Fig. 4. The specific temperature characteristic data are listed in Table 1. It can be seen from Fig. 4, Fig. 5 and table 1, with the addition of hydration heat inhibitor to concrete, the temperature rise of concrete decreases obviously and the temperature rise curve tends to flatten with the increase of the amount of hydration heat inhibitor. The occurrence time of temperature peak is delayed and the temperature difference between the internal surface of concrete decreases. This indicates that the hydration heat inhibitor can effectively delay the early hydration reaction process of cementing materials and reduce the hydration heat release rate, which is very beneficial to crack control of mass concrete. 


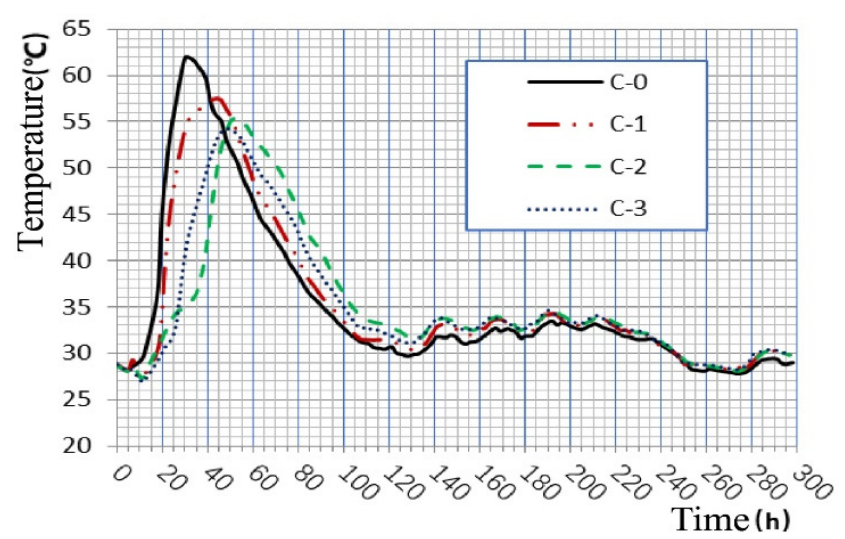

Fig. 3. Temperature rise curve of model concrete center

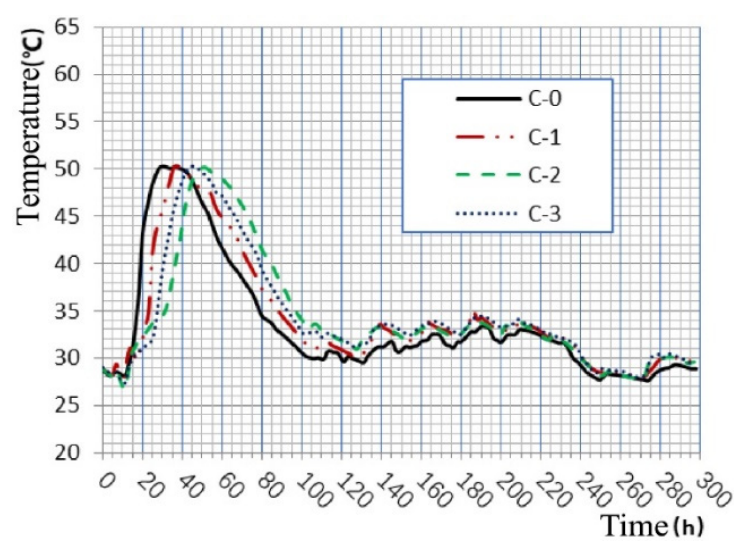

Fig. 4. Temperature rise curve of model concrete surface

Table 2. Temperature characteristic data of concrete with different dosage of hydration heat inhibitor

\begin{tabular}{c|c|c|c|c|c|c|c}
\hline No. & $\begin{array}{c}\text { Pouring } \\
\text { temp } \\
\left({ }^{\circ} \mathrm{C}\right)\end{array}$ & $\begin{array}{c}\text { Max. } \\
\text { temp }\left({ }^{\circ} \mathrm{C}\right)\end{array}$ & $\begin{array}{c}\text { Temp rise } \\
\left({ }^{\circ} \mathrm{C}\right)\end{array}$ & $\begin{array}{c}\text { Reduce temp } \\
\text { rise }\left({ }^{\circ} \mathrm{C}\right)\end{array}$ & $\begin{array}{c}\text { Temp peak } \\
\text { delay }(\mathrm{H})\end{array}$ & $\begin{array}{c}\text { Surface temp } \\
\left({ }^{\circ} \mathrm{C}\right)\end{array}$ & $\begin{array}{c}\text { Internal surface temp } \\
\text { difference }\left({ }^{\circ} \mathrm{C}\right)\end{array}$ \\
\hline $\mathrm{C}-0$ & 28.2 & 62.0 & 33.8 & 0 & 0 & 49.2 & 12.8 \\
\hline $\mathrm{C}-1$ & 27.7 & 57.6 & 29.9 & 3.9 & 14 & 49.1 & 8.5 \\
\hline $\mathrm{C}-2$ & 27.2 & 55.3 & 28.1 & 5.7 & 18 & 49.0 & 6.3 \\
\hline $\mathrm{C}-3$ & 27.3 & 54.2 & 26.9 & 6.9 & 22 & 49.1 & 5.1 \\
\hline
\end{tabular}

\subsection{Test results of concrete compressive strength}

The compressive strength test results of C50 concrete with different dosage of hydration heat inhibitor are listed in Table2. It can be seen from Table 2 that the early strength course of concrete after the addition of hydration heat inhibitor decreases, and the greater the dosage, the more obvious the strength decreases. This is because the heat of hydration inhibitors delay the early hydration reaction rate of cementified materials and thus reduce the early strength of concrete. When the dosage of hydration heat inhibitor reaches $1.5 \%$, the strength of concrete at $28 \mathrm{~d}$ and 56d also decreases obviously, which indicates that the excessive amount of hydration heat inhibitor has a certain adverse effect on the later strength of concrete.

Table 3. Influence of different dosage of hydration heat inhibitor on compressive strength of model concrete (MPa)

\begin{tabular}{c|c|c|c|c|c}
\hline No. Age & $3 \mathrm{~d}$ & $7 \mathrm{~d}$ & $14 \mathrm{~d}$ & $28 \mathrm{~d}$ & $56 \mathrm{~d}$ \\
\hline C-0 & 38.5 & 46.2 & 53.4 & 58.1 & 62.4 \\
\hline $\mathrm{C}-1$ & 33.6 & 43.7 & 50.9 & 56.5 & 60.1 \\
\hline $\mathrm{C}-2$ & 25.1 & 37.8 & 47.1 & 55.1 & 59.2 \\
\hline C-3 & 18.1 & 34.2 & 42.6 & 50 & 54.3 \\
\hline
\end{tabular}

\subsection{Results of workability test of concrete}

The concrete workability test is shown in Table 4. It can be seen from the table that after adding the hydration heat inhibitor, the slump and expansion loss of concrete are improved, and the initial setting time is increased. This is mainly because the hydration heat inhibitor inhibits the early hydration reaction rate of cementitious materials and delays the setting of concrete, thus playing a positive role in the working performance of concrete.

Table 4. Influence of different dosage of hydration heat inhibitor on concrete workability

\begin{tabular}{c|c|c|c|c|c}
\hline \multirow{2}{*}{ No. } & \multicolumn{2}{|c|}{ Slump (mm) } & \multicolumn{2}{c|}{ Expansion (mm) } & \multirow{2}{*}{$\begin{array}{c}\text { Initial setting } \\
(\mathrm{min})\end{array}$} \\
\cline { 2 - 5 } & initial & $60 \mathrm{~min}$ & initial & $60 \mathrm{~min}$ & \\
\hline $\mathrm{C}-0$ & 220 & 200 & 610 & 505 & 540 \\
\hline $\mathrm{C}-1$ & 220 & 205 & 605 & 520 & 565 \\
\hline $\mathrm{C}-2$ & 215 & 210 & 610 & 530 & 590 \\
\hline $\mathrm{C}-3$ & 210 & 195 & 615 & 550 & 620 \\
\hline
\end{tabular}

\subsection{Optimal dosage of heat of hydration inhibitor}

According to the above experimental results of temperature rise, compressive strength and working performance of concrete with hydration heat inhibitor, the optimal dosage of hydration heat inhibitor is preliminarily determined to be $1 \%$ of glue material. 


\section{Engineering application of hydration heat inhibitor}

\section{1 project overview}

An tunnel adopts two-way eight lane design, with a roof thickness of $150 \mathrm{~cm}$, a floor thickness of $150 \mathrm{~cm}$, a side wall thickness of $130 \mathrm{~cm}$, and a middle partition thickness of $80 \mathrm{~cm}$. There are altogether 28 segments with a length of $23.7 \mathrm{~m}$, a width of $37.9 \mathrm{~m}$, and a height of $10.1 \mathrm{~m}$. C50 concrete is used in the tunnel, and the content of glue material per cubic meter of concrete is $418 \mathrm{~kg}$. The concrete of the tunnel is poured in three times in height, that is, the cushion layer and bottom plate are poured first, then two side walls and two middle walls are poured, and finally the roof is poured. The time interval of each concrete pouring is about 30d, as shown in Fig.5. Five days after the casting of the first segment was completed, some cracks were found in both the side wall and the middle wall, the width of which was about $0.2 \mathrm{~mm}$, and water leakage appeared in different degrees. The crack distribution diagram of the side wall of the tunnel was shown in Fig.6.

\subsection{Causes of cracks and countermeasures}

According to the distribution of cracks in the side wall of the tunnel and the characteristics of penetration, it is analyzed that the cause of cracks is that the pouring time interval between the floor and the side wall concrete is too long. The poured bottom plate concrete will exert a strong constraint on the shrinkage and deformation of the side wall concrete, thus leading to cracking. According to the width and number of side wall cracks as well as tunnel segment length shown in Fig. 6, it can be calculated that the shrinkage strain that the side wall concrete needs to reduce is about $42.2 \times 10^{-6}$, which is equivalent to the concrete temperature change of about $4.2^{\circ} \mathrm{C}$. Therefore, according to the previous experimental results, in the subsequent to the construction of tunnel side wall concrete and the adhesive materials dosage is $1 \%$ of the heat of hydration inhibitors, if it can reduce the side wall of concrete internal temperature of $5.7^{\circ} \mathrm{C}$, theoretically, the goal of not cracking the side wall of the tunnel can be achieved, C50 concrete mixes containing heat of hydration inhibitors are listed in Table 5.

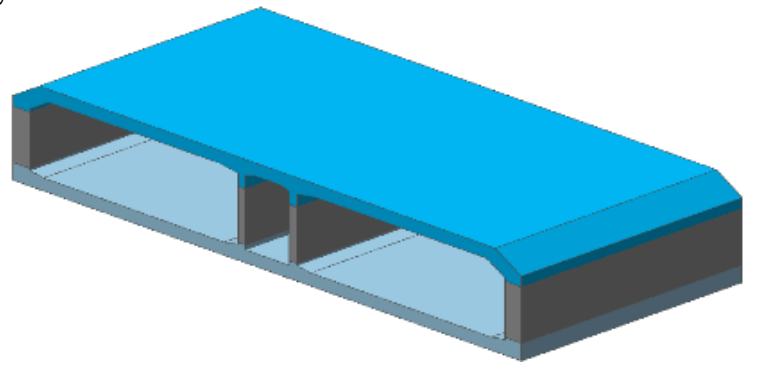

Fig. 5. Schematic diagram of finite element model of tunnel in weir construction section

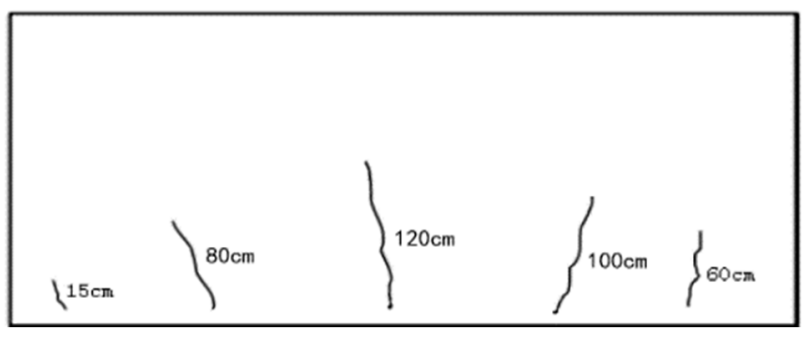

Fig. 6. Crack distribution diagram of side wall of a certain engineering tunnel

Table 5. C50 concrete mix proportion of a tunnel $\left(\mathrm{kg} / \mathrm{m}^{3}\right)$

\begin{tabular}{c|c|c|c|c|c|c|c}
\hline cement & Fly ash & Mineral powder & Sand & Crushed stone & Water & Water reducing agent & Inhibitor \\
\hline 273 & 84 & 63 & 780 & 1077 & 143 & 4.2 & 4.2 \\
\hline
\end{tabular}

\section{3 crack control effect}

The concrete mix proportion in Table 5 is applied in the construction of the second section of tunnel. The comparison of the temperature monitoring results of the side wall concrete center of the first and second sections is shown in Fig.7. It can be seen from Figure 7 that the temperature rise of the second section side wall is reduced by $5.9^{\circ} \mathrm{C}$ after adding $1 \%$ hydration heat inhibitor, and the arrival time of temperature peak is delayed by $8 \mathrm{~h}$. There is no crack in the side wall of the second section, and the crack control effect is good.

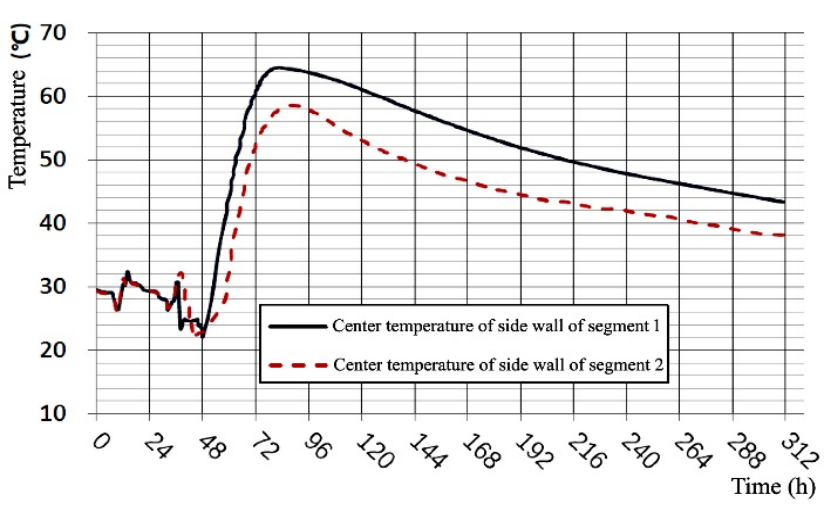

Fig. 7. Comparison of central temperature of side wall of section 1 and section

\section{Conclusion}

The results show that the heat of hydration inhibitor is a kind of additive which can effectively reduce the maximum temperature inside concrete and the shrinkage outside concrete. The application in crack control of mass 
concrete has the technical characteristics of low construction cost, simple operation and so on, and can be popularized in similar projects.

However, the heat of hydration inhibitor will have a certain influence on the early strength and late strength development of concrete and the workability of concrete, and the optimal mixing amount of heat of hydration inhibitor is about $1 \%$ of concrete cementing material.

\section{References}

1. WANG T.M.(1997 ) Some basic physical and mechanical properties of concrete. In: Yue w. (Eds.), Control of Engineering Structures. China Architecture and Building Press, Beijing. pp. 29-30.

2. Wang X.G.(2017) Basic physical properties of concrete. In: Xia W. (Eds.), Practical Calculation Method of Temperature Stress of Mass Concrete and Example of Crack Control Engineering. People's Communications Press, Beijing. pp.19-20.

3. An M.Z., Zhu J. (2001) Self-Shrinkage of High Performance Concrete. Journal of Building Materials, 4(2)159-166.

4. Yi J. (2020) Discussion on Temperature Crack Control in Mass Concrete Construction. Sichuan Cement, 12:29-30.

5. YAN Y.Y. (2020) Research on crack control technology of mass concrete. Green environmental protection building materials, 10:12-13.

6. Zhang X.G., Yang J.B. (2017) Research on Effect of Hydration Heat Inhibitor on Performance of Mass Concrete. Commercial Concrete, 5:33-35.

7. Hao B., Zhao W.L. (20170 Influence of hydration heat inhibitor on performance of mass concrete. Building Technology, 48:1073-1075. 